\title{
Undesirable compounds in oils and fats: analysis and regulation
}

Oléagineux, Corps Gras, Lipides. Volume 10, Numéro 2, 93-8, Mars 2003, ANALYSE

Auteur(s) : Florence LACOSTE Renée RAOUX, Institut des Corps Gras (ITERG), rue Monge, Parc Industriel, $\quad 33600$ PESSAC -- France $\quad$ Tel: + 33.(0)5.56.36.00.44 Fax: + 33.(0)5.56.36.57.60 $<$ f.lacosteiterg.com>.

\section{Author(s) : Florence LACOSTE Renée RAOUX}

Summary : The aim of this paper is to present, for some undesirable compounds representative of the major origins, a comparison between the efficiency of the analytical methods used (sensitivity, precision) and existing regulations. An idea of the different origins of the presence of undesirable compounds in oils and fats is given. Then a focus is done on guidelines on contaminant analysis provided by European directives or Codex Alimentarius. The reliability of some existing test methods compared to regulations is also examined: lead, hexane, polycyclic aromatic hydrocarbons, and pesticide residues.

Keywords : Analysis, contaminants, oils and fats, regulation, level of contamination

\section{ARTICLE}

Auteur(s) : Florence LACOSTE, Renée RAOUX

Institut des Corps Gras (ITERG), rue Monge, Parc Industriel, 33600 PESSAC - France Tel: + 33.(0)5.56.36.00.44

Fax: + 33.(0)5.56.36.57.60

$<$.lacoste@iterg.com>

\section{Introduction}

The presence of undesirable compounds in vegetable and animal oils and fats may have many different origins. Although the potential toxicity of most of these undesirable compounds is real, poisoning risks are rather limited due to the efficient elimination during oil-refining steps, careful conditioning, choice of efficient packaging and industrial quality control management.

Nevertheless, under the present economical conditions, product control can be used as an excuse to enforce artificial importation barriers. Therefore, disposal of highly sensitive and well validated analytical methods is essential to enhance export prospects. On the other hand, these analytical procedures have to be in concordance with the national, European and international regulations in terms of sensitivity and precision.

The aim of this paper is to present, for some undesirable compounds representative of the major origins listed above, a comparison between the efficiency of the analytical methods used (sensitivity, precision) and existing regulations.

First, an idea of the different origins of the presence of undesirable compounds in oils and fats will be presented. Then a focus will be done on guidelines on contaminant analysis provided by 
European directives or Codex Alimentarius. The reliability of some existing test methods compared to regulations will be examined afterwards.

\section{Origins of undesirable compounds}

The main origins of undesirable compounds in oils and fats are:

- Environment contamination, which is difficult to master,

- Crop protection, origin possible to keep under control,

- Production process, where conditions may be modified in order to reduce the formation of these undesirable compounds,

- Industrial utilisation, which may be oriented by information given to clients.

Environment contamination may lead to the presence of traces of heavy metals such as cadmium or lead. For the determination of these two elements in oils and fats, test methods were developed by the International Union of Pure and Applied Chemistry (IUPAC) and then standardised at international level: cadmium [1], lead [2].

Polychloro-biphenyls may also be found in fats, mainly in fish oils due to the contamination of the sea. Twelve congeners of this family of compounds have a high toxic effect, there are called "dioxin-like" due to their chemical structure. A European test method was developed for the analysis of both pesticides and PCBs [3-6].

Waste incineration can generate the presence of dioxins in the air which may contaminate crops or cattle. The analysis of dioxins is mainly focused on the determination of 7 polychlorodibenzodioxins and 10 polychloro-dibenzofurans showing the most toxic effect.

Crop protection needs to implement chemicals such as insecticides, fungicides or herbicides. The main families to be searched in fats and oils are: - Organochlorine residues such as lindane, still used in some countries, endosulfan, DDT, chlordane...

- Organophosphorus residues as fenthion, malathion, dichlorvos, pirimiphos methyl, methidathion...

- Pyrethrinoids like permethrin, cypermethrin or deltamethrin.

Along the production process some technical auxiliaries may be used such as catalysts for hydrogenation, for example nickel or chromium. It is also the case of hexane used for extraction of fat from meal, which content is generally highly reduced during oil-refining steps. For nickel and hexane test methods are standardised at the international and European levels:

EN ISO 8294 [7] for nickel, EN ISO 9832 [8] for hexane. Production process may lead to the formation of degradation products like polycyclic aromatic hydrocarbons (PAHs) when raw materials are dried by direct contact with combustion gases. Standards or project of standard dealing with PAHs are: ISO 15302 and ISO/CD $15753[9,10]$. Trans fatty acids (TFA) are mainly formed during hydrogenation or when deodorization step is conducted at too high the temperature. Standardised test method for TFA is EN ISO 15304 [11].

Transport and storage may be a source of contamination with mineral oil and chemicals from previous cargoes. Packaging may induce migration of monomer residues of plastics or solvents 
from inks. Two test methods are standardised for chlorinated solvents [12] (ISO 16035 JOCE $\mathrm{n}^{\circ}$ L248 p.1-83 5/09/91) and a proposal work item is studied for n-alkanes (ISO/PWI 21034) within ISO sub-committee working on oils and fats analysis (ISO/TC34/SC11). Industrial use like frying is known to produce various undesirable compounds such as triglycerides polymers or polar compounds which mainly correspond to oxidised mono-, diand triglycerides. Recently, the presence of acrylamide in fried products was reported by a Swedish team but there is no proof at the moment of the presence of this Maillard by-product in

frying

oils. Standardised methods do exist for polar compounds [13] and polymers of triglycerides [14]. It is not the case for acrylamide for the moment.

\section{Criteria for test method validation}

The determination of traces generally requires a two-step procedure to extract and concentrate and then analyse the compounds from the matrix. Criteria to be checked when validating a test method are: analytic range, sensitivity, selectivity, recovery through extraction, precision. Sensitivity may be expressed by the limit of quantification (LOQ), sometimes called limit of determination, which is the lowest concentration quantitatively measured, or by the lowest calibrated level

$(\mathrm{LCL})$.

Precision is expressed by the repeatability $(r)$ which covers repetition of independent tests done in the same lab, with the same operator in a short interval of time, and by the reproducibility $(R)$ which covers repetition of independent tests done in different labs, with different operators.

\section{Guidelines on contaminant analysis}

European regulations dealing with accepted limits $(A L)$ or maximum residue limits (MRL) for undesirable compounds are generally issued together with a directive specifying methods for sampling and analysis. These directives are guidelines to be followed in order to ensure the reliability of analytical results. Examples of these guidelines are presented in table 1: there are European directives for dioxins and PCBs, for pesticide residues, for cadmium and lead, and for aflatoxins.

Table 1. European directives for contaminants analysis

\begin{tabular}{|l|lrl|l}
\hline Dioxins and PCB & $\begin{array}{l}\text { European } \\
2002 / 69 / C E\end{array}$ & directive & Sampling \& analysis & 28/02/2003 \\
\hline $\mathrm{Pb}-\mathrm{Cd}$ & $\begin{array}{l}\text { European } \\
2001 / 22 / \mathrm{CE}\end{array}$ & directive & Sampling \& analysis & $05 / 04 / 2003$ \\
\hline Pesticide & $\begin{array}{l}\text { European } \\
99 / 333\end{array}$ & recommendation Quality control for residue \\
analysis &
\end{tabular}




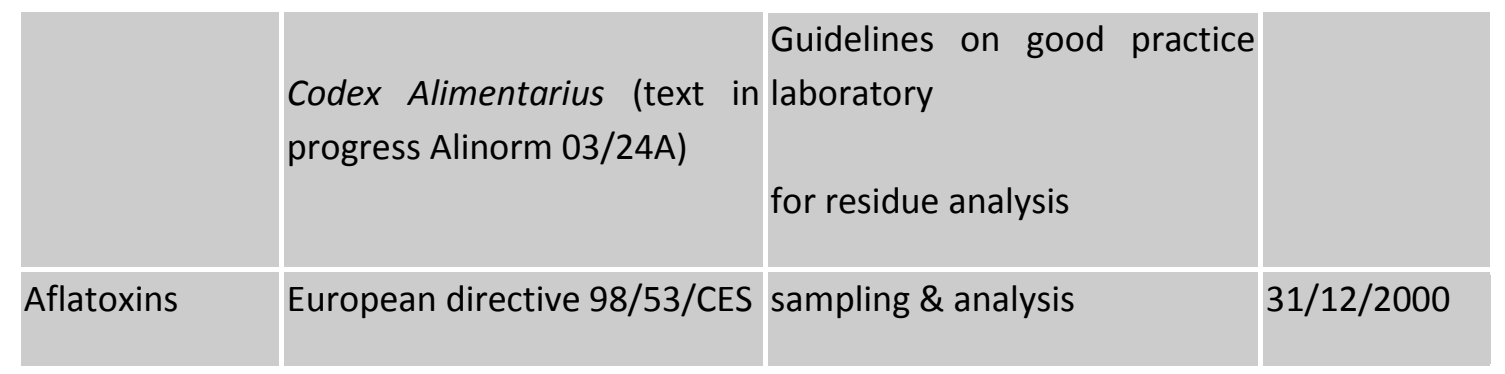

A revision of the guidelines issued by the Codex Alimentarius for pesticide residues is also in progress.

Most of the criteria specified in these guidelines were already presented before (table 2). Recovery through extraction is one of criteria specified more often than not in directives for analysis. The accepted range of variation of this parameter is generally $70-110 \%$ with some minor differences depending on the concentration to be measured from ppt level $(\mathrm{ng} / \mathrm{kg})$ to $\mathrm{ppb}$ level $(\mu \mathrm{g} / \mathrm{kg})$. Analytical range is sometimes specified with a range of variation from 0.5 to 2 times the accepted limit or MRL. limit of quantification should be one fifth of the accepted limit or between half to one-tenth of the lowest calibrated level. Precision is also part of the criteria present in European guidelines for contaminant analysis.

Table 2. European directives criteria for contaminants analysis

Recovery

\section{Analytical range}

\section{Limit of quantification (LOQ) Lowest calibrated level (LCL)}

$60-120 \%$ of dioxins (CE)

70-110\% of pesticides (CE) and aflatoxins (CE)

$50-120 \%$ to $70-110 \%$ for pesticides (CODEX)

$80-120 \%$ for $\mathrm{Pb}-\mathrm{Cd}$ (CE)

05-2 times the accepted limit (AL) for dioxins (CE)

LCL-2 times the MRL for pesticides (CODEX)

$$
\begin{aligned}
& L O Q=1 / 5 \text { of } A L \text { for dioxins }(C E) \\
& L O Q=1 / 5 \text { of } A L \text { for } P b-C d(C E) \\
& L C L=1 / 2 \text { to } 1 / 10 \text { of } M R L \text { for pesticides (Codex) }
\end{aligned}
$$

AL: Accepted limit; LCL: Lowest calibrated level; LOQ: Limit of quantification

Table 3 presents some definitions necessary to estimate the precision of a test method: $-R$ is the reproducibility directly linked to the standard deviation calculated from the raw data of an international or European collaborative study, - RSDR is the relative standard deviation for reproducibility calculated by the ratio of standard deviation (SDR) on mean value, expressed in percentage.

Table 3. Precision and Limit for performance acceptability - Definitions

$\mathbf{R}$

RSDR
Reproducibility $(2.8 \times$ SDR $)$

Relative SD for reproducibility (SDR/mean value in \%)

RSDR Horwitz RSDR Horwitz $=2(1-0.5 \log C)$ with $C$ in $\mathrm{g} / \mathrm{g}$ 


\section{Horrat $\mathbf{R}$ value $\quad$ RSDR ring test/RSDR Horwitz}

SD: standard deviation; SDR: standard deviation for reproducibility.

The Horwitz publication issued in 1982 gave an empirical formula for reproducibility based on 150 AOAC ring tests (table 3). This formula allows calculating an "expected" relative standard deviation in function of the concentration of the analyte being determined. The Horwitz RSDR may be used to estimate the performance acceptability of a new test method compared to results generally obtained within a ring test.

Figure 1 graphically presents the relationship between Horwitz RSDR and concentration. For example, Horwitz RSDR is equal to $45 \%$ for a concentration of $1 \mu \mathrm{g} / \mathrm{kg}$ (ppb level) and falls to $16 \%$ when the concentration increases up to $1 \mathrm{mg} / \mathrm{kg}$ (ppm level).

How to use Horwitz relative standard deviation? By calculating a ratio between the RSDR obtained with the ring test of the new method and the RSDR calculated with Horwitz empirical formula. This ratio is called Horrat value.

According to European guidelines on sampling and analysis (table 4), Horrat value should be: lower than 1.5 for lead and cadmium, between 1 and 2 for aflatoxins, or between 0.5 and 2 for general AOAC guidelines for collaborative study procedures to validate a method of analysis.

Table 4. Limit for performance acceptability given by European directives for contaminants analysis

$$
\begin{array}{ll}
= & \text { RSDR Horwitz for pesticide residues (CODEX) } \\
& <1.5 \text { for } \mathrm{Pb}-\mathrm{Cd}(\mathrm{CE}) \\
\text { Horrat value } \quad & =1 \text { to } 2 \text { for aflatoxins (CE) } \\
& =0.5-2(\mathrm{AOAC})
\end{array}
$$

The third part of this paper is focused on a review of reliability of existing methods using the criteria previously listed.

\section{Evaluation of contaminant test methods: examples}

\section{Determination of lead in oils and fats}

The first test method presented is the determination of lead in oils and fats using the EN ISO 12193 standard based on furnace atomic absorption (table 5). European regulation requires a maximum accepted limit of $0.1 \mathrm{mg} / \mathrm{kg}$ in oils and fats. Limit of quantification is ten times lower than the maximum accepted limit so the standard is in accordance with European guidelines.

Table 5. Evaluation of standardised test method for lead in fats and oils

$\begin{array}{llll}\text { LOQ } & 0.010 \mathrm{mg} / \mathrm{kg} & 1 / 10 \times \mathrm{AL} & \text { yes } \\ \mathrm{R}(0.1 \mathrm{mg} / \mathrm{kg}) & 0.068 \mathrm{mg} / \mathrm{kg} & \text { Horrat } \mathrm{R}=3.0 \text { no }\end{array}$


$\operatorname{RSDR}(0.1 \mathrm{mg} / \mathrm{kg}) \quad 68 \%$

RSDR Horwitz $\quad 23 \%$

LOQ: limit of quantification; AL: accepted limit

Reproducibility measured at the maximum accepted limit is $0.068 \mathrm{mg} / \mathrm{kg}$ which leads to a RSDR equal to $68 \%$ issued from the ring test. Comparison to the Horwitz RSDR calculated for a $0.1 \mathrm{mg} / \mathrm{kg}$ level leads to a Horrat value of 3 which is higher than the 1.5 limit fixed by the European directive. The conclusion is that the standardised test method is sensitive enough but not precise enough.

To give an idea of the contamination of edible oils and fats, some results are presented in table 6 for refined oils, virgin oils and animal fats. More than $98 \%$ of samples analysed present a concentration of lead under $0.02 \mathrm{mg} / \mathrm{kg}$ and all results are lower than the maximum accepted limit of $0.1 \mathrm{mg} / \mathrm{kg}$, so we may conclude that lead contamination is a not a real problem in oils and fats.

Table 6. ITERG survey on lead in edible oils and fats (1992-1999)

$\begin{array}{llll}\text { Refined oils } & \text { Virgin oils } & \text { Animal fats } & \\ \text { Number of samples } & 42 & 54 & 22 \\ \mathrm{~Pb} \leq 0.02 & 100 \% \text { samples } & 98 \% \text { samples } & 95 \% \text { samples } \\ <\mathrm{Pb} \leq 0.10 & - & 1 \text { sample } & 1 \text { sample } \\ \mathrm{Pb}>0.10 & - & - & -\end{array}$

\section{Determination of hexane in oils and fats}

The second example deals with the determination of hexane in oils and fats using static headspace combined with gas chromatography analysis (table 7). Two test methods are standardised: the EN ISO 8294 [7] method mostly for all processed oils (crude or refined) and the French standard NF T 60-257 [15] dedicated to low level of hexane in refined oils. European regulation limits the hexane content in oils and fats to $1 \mathrm{mg} / \mathrm{kg}$. Limits of quantification specified in both scopes of the two standards are higher than the maximum accepted limit: respectively 10 and $2 \mathrm{mg} / \mathrm{kg}$, compared to the limit of $1 \mathrm{mg} / \mathrm{kg}$.

Table 7. Evaluation of standardised test method for hexane in fats and oils

ISO

$$
\text { // guidelines NF // guidelines }
$$

LOQ $\mathrm{mg} / \mathrm{kg}$ (scope) $\quad 10$

$>\mathrm{AL}$

2

LOQ $\mathrm{mg} / \mathrm{kg}$ (ring

1.6

2

$>\mathrm{AL}$ 
test)

RSDR (1.6 \&

$2 \mathrm{mg} / \mathrm{kg}$ )

$39 \%$

$\%$

Horrat $\mathrm{R}=2.9$

Horrat R $=1.6$

RSDR Horwitz

$15 \%$

$14 \%$

LOQ: limit of quantification; AL: accepted limit.

Looking at the Horrat ratios, EN ISO 8294 [7] presents a 2.9 value and NF T 60-257 [15] method a value of 1.6. Based on the AOAC guidelines, EN ISO 8294 [7] is not precise enough whether NF T 60-257 [15] standard is precise enough.

\section{Determination of PAHs}

There is no European regulation for PAHs but an industrial code of practice was provided by FEDIOL which is the European association of oilseed crushers (table 8). In short this code defines a maximum level for total and heavy PAHs content. It also specifies that when benzo(a)pyrene content in crude oil is higher than $1 \mu \mathrm{g} / \mathrm{kg}$, an additional treatment of the oil during refining is necessary.

Table 8. Regulations for polycyclic aromatic hydrocarbons

Total PAHs $\leq 25 \mu \mathrm{g} / \mathrm{kg}(10-9 \mathrm{~g} / \mathrm{g})$ or heavy PAHs $\leq 5 \mu \mathrm{g} / \mathrm{kg}$

If $\mathrm{B}(\mathrm{a}) \mathrm{P}$ in crude oil $>1 \mu \mathrm{g} / \mathrm{kg} \rightarrow$ additional treatment necessary

Spain \& Italy: regulation on pomace olive oil

PAHs: B(a)P - B(e)P - B(a)A - B(b)F - B(k)F - DB(a,h)A - B(g,h,i)P - I(1,2,3,c-d)P-

Each $\mathrm{PAH} \leq 2 \mu \mathrm{g} / \mathrm{kg}$ - Sum of PAHs $\leq 5 \mu \mathrm{g} / \mathrm{kg}$

Regulations in Spain and Italy do exist for pomace olive oil and it concerns eight heavy PAHs listed in table 8. Each PAH is limited to $2 \mu \mathrm{g} / \mathrm{kg}$ and their sum should be lower than $5 \mu \mathrm{g} / \mathrm{kg}$.

The only test method already standardised [9] deals with the determination of benzo(a)pyrene. A committee draft test method is under evaluation within ISO for determination of 12 PAHs (table 9). Limits of quantification are respectively 0.1 and $0.2 \mu \mathrm{g} / \mathrm{kg}$ for these test methods which are in accordance with general guidelines.

Table 9. Evaluation of standardised test methods for polycyclic aromatic hydrocarbons (benzo(a)pyrene used as marker)

ISO 15302

// guidelines ISO CD 15753 


$\begin{array}{lcll}\text { LOQ B (a)P }(\mu \mathrm{g} / \mathrm{kg}) & 0,1 & 1 / 10 \times \mathrm{AL} & 0,2 \\ \text { RSDR }(1 \mu \mathrm{g} / \mathrm{kg}) & 41 \% & \text { Horrat R }=0.9 & \text { not evaluated yet } \\ \text { RSDR Horwitz } & 45 \% & \end{array}$

LOQ: limit of quantification; AL: accepted limit

Benzo(a)pyrene determination test method presents a Horrat ratio of 0.9, so ISO 15302 [9] can be considered as enough sensitive and enough precise. Precision of the multi-PAHs method is not evaluated yet.

Looking at the results for a spiked rapeseed oil of an experimental French proficiency test on PAHs determination (table 10), one can notice that Horrat values are between 1.4 to 2.1 depending on the analyte determined. Regarding the AOAC general guidelines, the dispersion of the laboratories is acceptable.

Table 10. French proficiency test (BIPEA): results for a rapeseed oil spiked with polycyclic aromatic hydrocarbons

$\begin{array}{lccccc}\text { Ref. value } & \text { Nb labs } & \text { RSD\% } & \text { Horwitz\% } & \text { Horrat } & \\ \text { B(a)Anthracene } & 4 & 10 & 50 & 37 & 1.4 \\ \text { B(b)Fluoranthene } & 10 & 10 & 70 & 32 & 2.1 \\ \text { B(K)Fluoranthene } & 22 & 12 & 48 & 28 & 1.7 \\ \text { B(a)Pyrene } & 16 & 13 & 62 & 30 & 2.1 \\ \text { DB(a,h)Anthracene } & 7 & 11 & 64 & 34 & 1.9 \\ \text { B(g,h,i)Perylene } & 12 & 12 & 54 & 31 & 1.7 \\ \text { I(1,2,3,c-d)Pyrene } & 12 & 12 & 54 & 31 & 1.7\end{array}$

Evaluation of the contamination of different vegetable oils collected around Europe and even further is presented in table 11. Depending on the nature of the seed, $67 \%$ to $100 \%$ of the samples present a total concentration for heavy PAHs lower than the $5 \mu \mathrm{g} / \mathrm{kg}$ limit. These figures mean that the oils are globally safe regarding PAHs contamination but it also shows that seeds are not equally protected.

Table 11. ITERG study on polycyclic aromatic hydrocarbons in refined vegetable oils (2000)

\section{Sunflower oil Rapeseed oil Grape seed oil}

$\begin{array}{llll}\text { Number of samples } & 12 & 7 & 12\end{array}$




$\begin{array}{llll}\text { Sum } \leq 5 \mu \mathrm{g} / \mathrm{kg} & 83 \% \text { samples } & 100 \% \text { samples } & 67 \% \text { samples } \\ \text { Sum }>5 \mu \mathrm{g} / \mathrm{kg} & 2 \text { samples } & - & 4 \text { samples }\end{array}$

\section{Determination of pesticide residues}

The last example deals with pesticides. For vegetable oils, there is no maximum residue limit fixed at the European level. At the French level, only limits are specified for prochloraze, procymidone and vinclozoline (table 12).

Table 12. Regulations on pesticides

- no MRL for vegetable oils

\section{French level}

- MRL prochloraze $=1 \mathrm{mg} / \mathrm{kg}$ sunflower oil (SFO)

- MRL procymidone $=5 \mathrm{mg} / \mathrm{kg}$ rapeseed oil (RO)

$-\mathrm{MRL}$ vinclozoline $=0.5 \mathrm{mg} / \mathrm{kg}$ rapeseed oil $(\mathrm{RO})$

\section{Codex Alimentarius MRLs (mg/kg)}

\begin{tabular}{|c|c|c|c|}
\hline Dimethoate (refined OO) & $0.05^{*}$ & Dimethipin (edible SFO) & $0.02 *$ \\
\hline Fenthion (virgin OO) & 1 & Paraquat (crude or edible SFO) & $0.05^{*}$ \\
\hline Methidathion (virgin OO) & 2 & Permethrine (crude or edible SFO) & 1 \\
\hline Parathion (virgin OO) & 2 & Procymidone (edible SFO) & 0.5 \\
\hline Aldicarbe (edible PO) & $0.01 *$ & Chlordane (crude or edible SBO) & $0.05 / 0.02$ \\
\hline Phorate (crude or edible PO) & $0.05^{*}$ & Heptachlore (edible SBO) & 0.02 \\
\hline $\begin{array}{l}\text { Pyrimiphos-methyl (crude } \\
\text { edible PO) }\end{array}$ & or ${ }_{15}$ & Profenofos (edible SBO) & $0.05^{*}$ \\
\hline Methoprene (edible corn O) & $0.2^{*}$ & $\begin{array}{l}\text { Glufosinate ammonium (crude RO and } \\
\text { SFO) }\end{array}$ & $0.05^{*}$ \\
\hline Cypermethrine (edible O) & 0.5 & Terbufos (crude RO) & 0.05 \\
\hline
\end{tabular}

OO: olive oil; SFO: sunflower oil; RO: rapeseed oil; SBO: soybean oil; PO: peanut oil; *MRL at or about $L O Q$

The Codex Alimentarius list of MRLs for pesticide residue in oils and fats is much more developed (table 12). In short molecules are grouped in this table according to the type of oil. For example, for olive oil, there are limits put for dimethoate, fenthion, methidathion and parathion. Limits do exist also for corn oil, sunflower oil, rapeseed oil, peanut oil and soybean 
oil. It is noticeable that cypermethrine residue is limited for all edible oils. Some of these values are fixed at or about the limit of quantification.

The European standard for pesticides and PCB residues determination in fatty products is EN 1528 part 1 to 4 [3-6]. Part 1 deals mainly with generalities and good laboratory practice. Part 2 is focused on extraction of fat for food products such as methods for milk, butter, cheese and dairy, meat and fish or eggs. Part 3 describes 8 methods for clean-up of the extracts based on:

- liquid/liquid extraction followed by florisil purification (AOAC, Specht)

- Florisil chromatography (AOAC, Stijve)

- Aluminium oxide chromatography (Greve \& Grevenstuk).

Part 4 presents determination and confirmatory tests using gas chromatography with electron capture detection, phosphorus detection or mass spectrometry detection. In part 1 of the European standard, some recommendations are given for acceptable reproducibility relative standard deviation (table 13).

Table 13. Recommendation for acceptable reproducibility given by EN 1528-1 (fatty foodDetermination of pesticides and $P(B)$

$\begin{array}{llllll}\text { R } & \text { RSDR } & \text { RSDR Horwitz } & \text { Horrat } & \text { //guidelines } \\ 0.01 & 0.01 & 36 \% & 32 \% & 1.1 & \\ 0.1 & 0.05 & 18 \% & 23 \% & 0.8 & \text { Yes (Codex) } \\ 1.0 & 0.25 & 9 \% & 16 \% & 0.6 & \end{array}$

For example, at a level of $0.1 \mathrm{mg} / \mathrm{kg}$, the recommended relative standard deviation should be at about $18 \%$, which is lower than the Horwitz [16] empirical RSRD. So this standard requires better precision than the one generally observed in ring tests. Recovery through extraction should be in the range of 70 to $110 \%$ in accordance with European directive dealing with pesticide residues. The limit of quantification required by the EN standard depends on the MRL level: one tenth of the MRL in general case, and one fifth of the MRL for MRL lower than $0.05 \mathrm{mg} / \mathrm{kg}$. In order to give an idea of the general level of contamination of vegetable oils regarding pesticide residues, the results of two different studies are presented. Our first study is focused on organophosphorus pesticide residues in virgin olive oils sold or imported in France (table 14). More than $80 \%$ of the 160 samples analysed show no contamination. Fenthion is the most present residue but all samples are under the tenth of the MRL fixed by Codex Alimentariusat $1 \mathrm{mg} / \mathrm{kg}$. This study shows that traces of pesticide residues in virgin olive oils are really low compared to regulation limits.

Table 14. ITERG study (1997/98) on organophosphorus residues in virgin olive oils (VOO) 


\begin{tabular}{lll} 
VOO sold in France & VOO & \multicolumn{1}{c}{ imported } \\
& in France & 111 \\
Number of samples & 49 & $84 \%$ samples \\
No contamination & $81 \%$ samples & $16 \%$ samples \\
Fenthion $<0.1 \mathrm{mg} / \mathrm{kg}$ & $13 \%$ samples & \\
& $\begin{array}{l}5 \text { samples } \\
\text { Chlorpyrifos }(<0.2 \mathrm{mg} / \mathrm{kg})\end{array}$ & $\begin{array}{l}1 \text { sample } \\
\text { Diazinon }(<0.04 \mathrm{mg} / \mathrm{kg})\end{array}$ \\
Other residues & Lindane $(<0.02 \mathrm{mg} / \mathrm{kg})$ &
\end{tabular}

The second study deals with organochlorine and organophosphorus pesticide residues in crude and refined vegetable oils (table 15). Only $11 \%$ of the crude oils examined present a total contamination under the limit of quantification. On the other hand, all refined samples have a total contamination under the limit of quantification. Residues found in crude vegetable oils are mainly malathion, dichlorvos and fenitrothion with a total contamination lower than $0.9 \mathrm{mg} / \mathrm{kg}$. The main conclusion of this second study is that refining is very efficient for pesticide residues elimination.

Table 15. ITERG study on pesticide residues in vegetable oils (1994/96)

\begin{tabular}{|l|l|l|}
\hline \begin{tabular}{|l|l|} 
Total contamination \\
(OP + OC)
\end{tabular} & Crude oils & Refined oils \\
\hline Number of samples & 29 & 13 \\
\hline TC $<$ LOQ & $11 \%$ samples & $100 \%$ samples \\
\hline TC $<0.1 \mathrm{mg} / \mathrm{kg}$ & $43 \%$ samples & - \\
\hline TC $<0.9 \mathrm{mg} / \mathrm{kg}$ & $46 \%$ samples & - \\
\hline
\end{tabular}

OP: organophosphorus residues; OC: organochlorine residues; LOQ: limit of quantification.

\section{Conclusion}

The main conclusions of this paper are:

- First of all, that European and international regulations take into account good laboratory practice by fixing criteria for test method performance acceptability.

- Second, for most of the undesirable compounds possibly found in oils and fats, standardised test methods do exist or are in progress. 
- Third, results presented prove that oil-refining steps are efficient for elimination of most undesirable compounds.

- Lastly, it needs to be noted that oils and fats present in general low level of undesirable compounds such as lead, cadmium, hexane, PAHs or pesticide residues.

\section{RÉFÉRENCES}

1. EN ISO 15774: 2001. Animal and vegetable fats and oils. Determination of cadmium content by direct graphite furnace atomic absorption spectrometry.

2. EN ISO 12193: 1999. Animal and vegetable fats and oils. Determination of lead content. Graphite furnace atomic absorption method.

3. EN 1528-2: 1996. Fatty food. Determination of pesticides and polychlorinated biphenyls (PCBs). Part 1: general.

4. EN 1528-3: 1996. Fatty food. Determination of pesticides and polychlorinated biphenyls (PCBs). Part 2: extraction of fat, pesticides and PCBs, and determination of fat content.

5. EN 1528-4: 1996. Fatty food. Determination of pesticides and polychlorinated biphenyls (PCBs). Part 3: clean-up methods.

6. EN 1528-1: 1996. Fatty food. Determination of pesticides and polychlorinated biphenyls (PCBs). Part 4: determination, confirmatory tests, miscellaneous.

7. EN ISO 8294: 1999. Animal and vegetable fats and oils. Determination of copper, iron and nickel contents. Graphite furnace atomic absorption method.

8. EN ISO 9832: 2000. Animal and vegetable fats and oils. Determination of residual technical hexane content.

9. ISO 15302: 1998. Animal and vegetable fats and oils. Determination of benzo[a]pyrene content. Reverse-phase high performance liquid chromatography method.

10. ISO/CD 15753. Animal and vegetable fats and oils. Determination of polycyclic aromatic hydrocarbons (Committee Draft).

11. EN ISO 15304: 2002. Animal and vegetable fats and oils. Determination of the content of trans fatty acid isomers of vegetable fats and oils. Gas chromatographic method.

12. ISO 16035: 2003. Animal and vegetable fats and oils. Determination of low-boiling halogenated hydrocarbons in edible oils.

13. EN ISO 8420: 2002. Animal and vegetable fats and oils. Determination of content of polar compounds.

14. EN ISO 16931: 2001. Animal and vegetable fats and oils. Determination of polymerized triglycerides content by high-performance size-exclusion chromatography (HPSEC). 
15. NF T 60-257: 1998. Animal and vegetable fats and oils. Determination of low content of residual technical hexane.

16. HORWITZ W. "Evaluation of analytical methods used for regulation of foods and drugs", Analytical Chemistry 1982; vol. 54, n¹, 67 A-76 A.

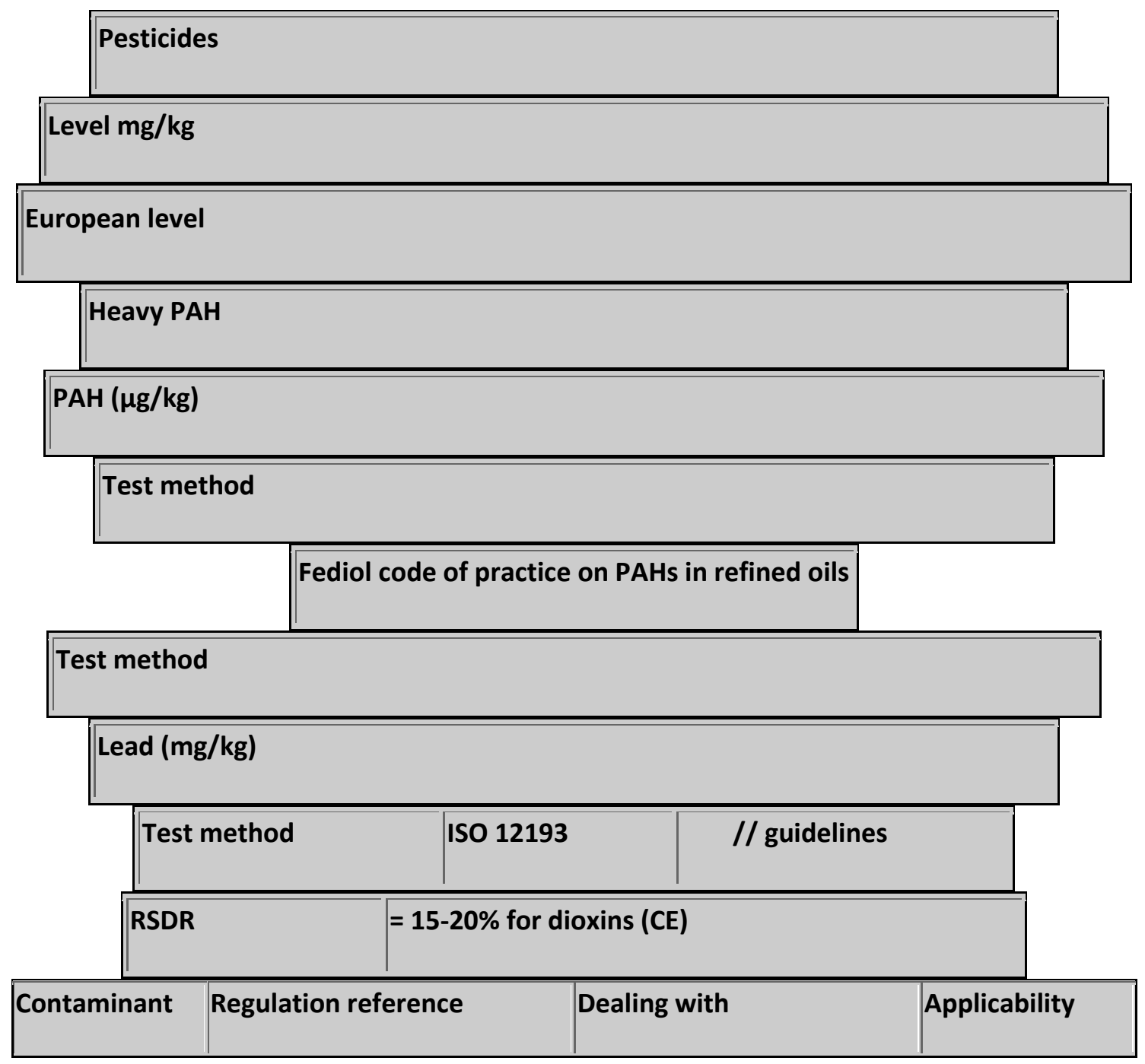




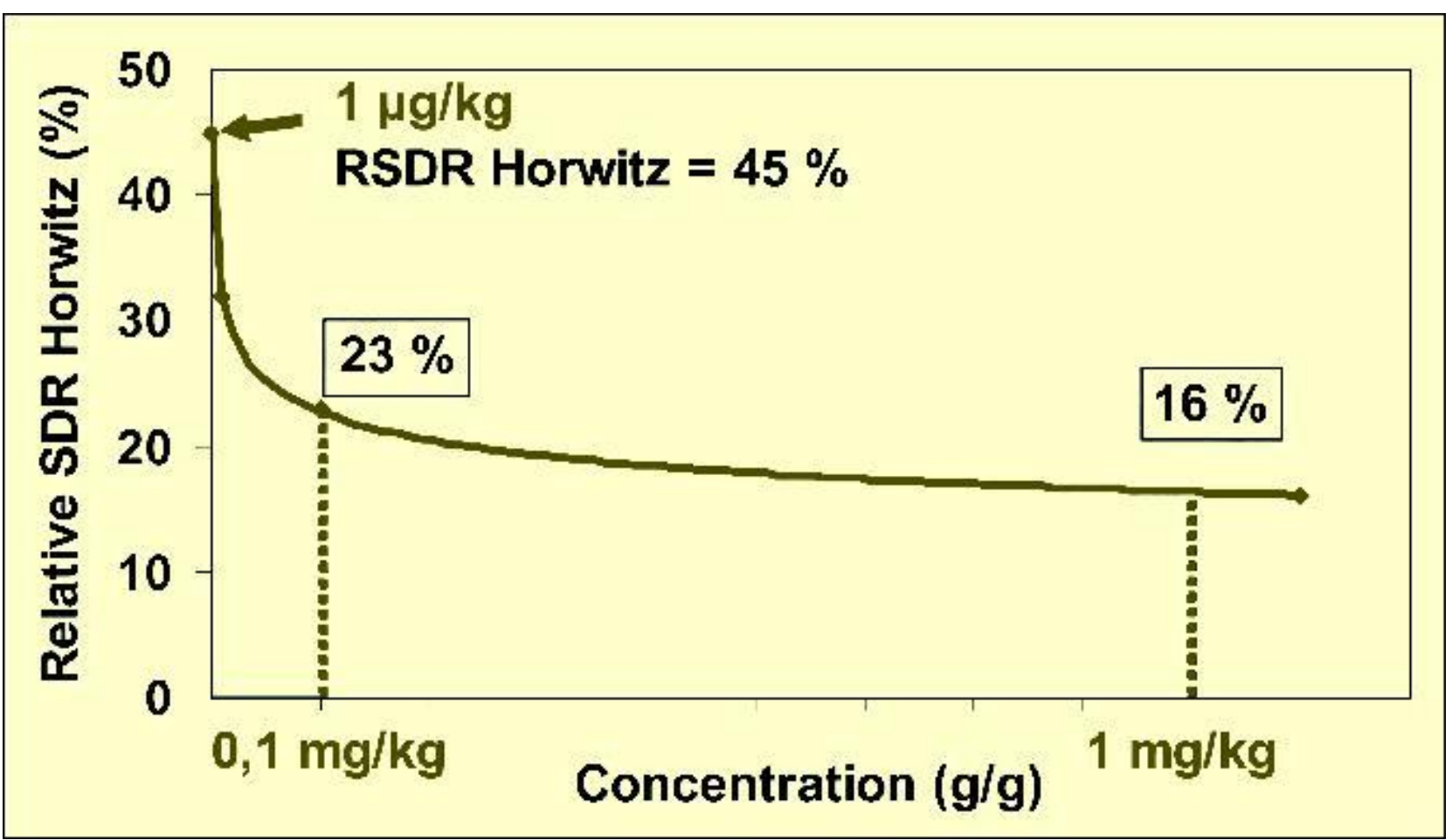

Figure 1. Relationship between relative standard deviation of reproducibility (RSDR) and concentration according to Horwitz formula 